\title{
Quantitative Assessment of City's Smart Growth Level in China Using Fuzzy Comprehensive Evaluation
}

\author{
Jie Min ${ }^{1}$, Baoquan Cheng, a, Shunxiang Gao ${ }^{2}$, Zhenjie Luo ${ }^{2}$, Kai Zhu ${ }^{2}$ and Bingbin Liu ${ }^{2}$ \\ ${ }^{1}$ School of Mathematics and physics Sciences, Anhui Jianzhu University, 234601 Hefei, Anhui Province, China \\ ${ }^{2}$ School of Civil engineering, Anhui Jianzhu University, 234601 Hefei, Anhui Province, China
}

\begin{abstract}
In this paper we develop an indicator system to evaluate the Smart Growth Level based on 3E's principles and calculate the Smart Growth Level of 70 mid-scale and large cities in China using fuzzy comprehensive evaluation model. We also divide these cities into four grades: outstanding, good, normal and terrible. The results are significant for governments to design a reasonable development plan.
\end{abstract}

\section{Introduction}

Urban Sprawl is low-density, non-continuous, automobile-dependent residential and non-residential development model, which needs to cost a remarkable amount of land and other natural resources. In china, this unsustainable development model has affected many cities recently, which brought several problems with environment, economy as well as society [1]. Smart growth is an urban planning theory that originated in 1990 's as a means to curb continued urban sprawl and reduce the loss of farmland surrounding urban centres, which focuses on building cities that embrace the E's of sustainability-Economically prosperous, socially Equitable, and Environmentally Sustainable [2]. Therefore, the problem how to use the checking data to evaluate the Chinese cities' Smart Growth Level (SGL) has been the public concern.

Badill et al illustrated the work in the context of SiiMobility smart city project, which is to define a smart city architecture. A wide range of processes and data is presented [3]. Anna Luusua et al introduced a new way of designing called nonanthropocentric design to decenter the human as the focus of design while the smart city agenda is critique for its focus on technology and business led solutions [4]. Chang Saisai et all proposed a fuzzy comprehensive evaluation model based on Analytic Hierarchy Process(AHP) to judge whether a city's growth plan is reasonable [5].

In this paper, we studied the SGL of 70 large and mid-scale cities in China to find the one that the City Sprawl is the most serious, which can give some constructive suggestions when the government makes a new development plan.

\section{Gathering SGL elements}

\subsection{Data Collection}

Collecting sufficient data is the basis of developing a complete index system. We searched the China Economic and Social Development Statistics Database [6] and found 22 indicators of 70 mid-scale and large cities firstly based on 3E's principles.

\subsection{Data filling}

It is important to ensure the continuity and authenticity of research data. However, some data is missing because not all data is provided in the website. To address this problem, two methods are proposed to complete the data, which are as follow,

\subsubsection{Average value}

If we can found the data of an indicator for most of cities except few cities, the average value of other cities can be taken as the missing. For example, the number of public libraries in Dali is missing so we adopt the average value of other 69 cities to replace it. As these figures are really few, it affects little to the the evaluation result.

\subsection{2 $\operatorname{GM}(1,1)$ model}

As the frequently used grey model, $\operatorname{GM}(1,1)$ is particularly available to such random unconfirmed issue. If the data before can be obtained, $\operatorname{GM}(1,1)$ Model is adopted to predict the figures we need. For example, the data for Rural Subsistence Expenditure, Total Import and Export, Urban Social Security Engagement Rate, Expenditure on Education Expenditure, Number of Health Institutions in Hefei in 2015 is missing while the

\footnotetext{
a Corresponding author: author@e-mail.org
} 
figures before are available, so $\operatorname{GM}(1,1)$ Model is used to forecast the figures[7].

Assume that

$$
X^{(0)}=\left[x^{(0)}(1), x^{(0)}(2), \ldots . ., x^{(0)}(n)\right]
$$

is a sequence of raw data, its 1-AGO sequence $x^{(1)}$ is

$$
\begin{gathered}
X^{(1)}=\left[x^{(1)}(1), x^{(1)}(2), \ldots . ., x^{(1)}(n)\right] \\
x^{(1)}(k)=\sum_{i=0}^{k} x^{(0)}(i), k=1,2, \ldots n
\end{gathered}
$$

and the sequence mean generated of consecutive neighbors $x^{(1)}$ is

$$
Z^{(1)}=\left[z^{(1)}(2), z^{(1)}(3), \ldots \ldots, z^{(1)}(n)\right]
$$

Where

$$
z^{(1)}(k)=0.5 x^{(1)}(k+1)+0.5 x^{(1)}(k), k=2,3, \ldots n
$$

and the 1-IAOG sequence of $\alpha^{(1)} X^{(0)}$ of $X^{(0)}$ is

$$
\begin{gathered}
\alpha^{(1)} X^{(0)}=\left(\alpha^{(1)} x^{(0)}(1), \alpha^{(1)} X^{(0)}(2), \ldots ., \alpha^{(1)} X^{(0)}(n)\right) \\
\alpha^{(1)}(k)+\alpha z^{(1)}(k)=b
\end{gathered}
$$

is called a grey differential equation, and is also called the model $\operatorname{GM}(1,1)$.

The equation

$$
\frac{d x^{(1)}}{d t}+\alpha x^{(0)}=b
$$

is called a whitenization equation of the grey differential Equation.

The result is shown in Figure. 1 to Figure.5 and Table.1.

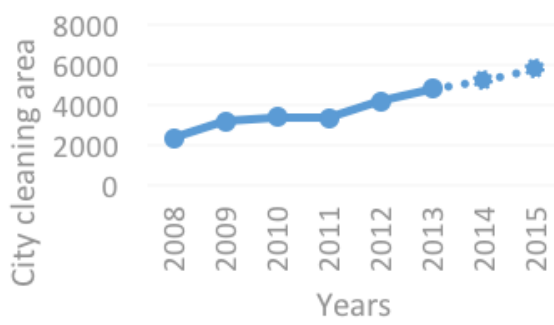

Figure. 1.The prediction of City cleaning area.

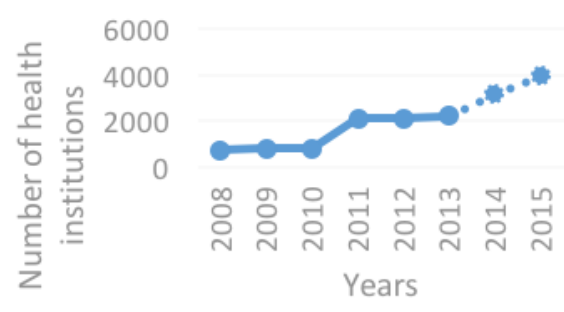

Figure. 2.The prediction of Number of heath institutions.

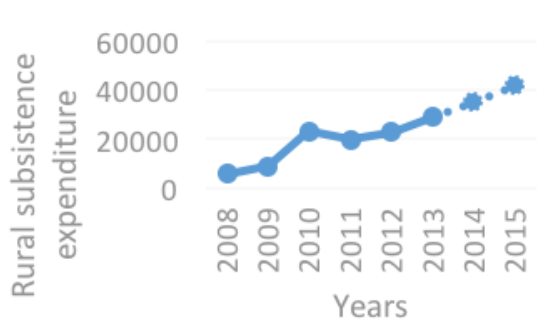

Figure. 3. The prediction of Rural subsistence expenditure.

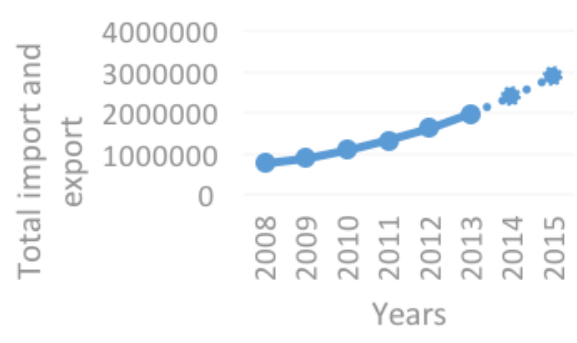

Figure. 4. The prediction of Total import and export

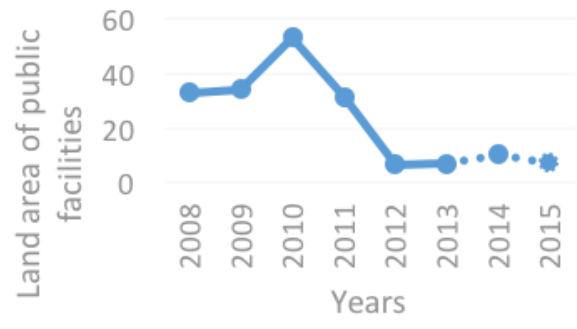

Figure. 5. The prediction of Land area of public facilities.

\begin{tabular}{|c|c|}
\hline Indicators & Absolute error \\
\hline $\begin{array}{c}\text { Rural Subsistence } \\
\text { Expenditure } \\
(10,000 \text { yuan) }\end{array}$ & $0.00579 \%$ \\
\hline $\begin{array}{c}\text { Total Import and Export } \\
\text { (ten thousand US dollars) }\end{array}$ & $0.09882 \%$ \\
\hline $\begin{array}{c}\text { Urban Social Security } \\
\text { Engagement Rate. (\%) }\end{array}$ & $0.09658 \%$ \\
\hline $\begin{array}{c}\text { Expenditure on } \\
\text { Education Expenditure } \\
\text { (10,000 yuan) }\end{array}$ & $0.41376 \%$ \\
\hline $\begin{array}{c}\text { Number of Health } \\
\text { Institutions (unit) }\end{array}$ & $0.04802 \%$ \\
\hline
\end{tabular}

The results show that using the $\operatorname{GM}(1,1)$ model to forecast the missing data involves a smaller sample and less information. It's easier to build the model and the prediction precision is better. 


\section{Primary indicator system}

\subsection{Select indicators}

22 initial indicators are selected to evaluate the SGL of cities based on 3 E's principles refers to Economically prosperous, socially Equitable, and Environmentally Sustainable [8]-[11]. The indicator system is shown in Table.2.

Table. 1.Indicator system of SGL.

\begin{tabular}{|c|c|c|}
\hline $\begin{array}{l}\text { First } \\
\text { laver }\end{array}$ & Second lever & Third layer \\
\hline \multirow{22}{*}{$\begin{array}{c}\text { Smart } \\
\text { Growth } \\
\text { Level }\end{array}$} & \multirow{6}{*}{$\begin{array}{l}\text { Economic } \\
\text { prosperity }\end{array}$} & Per Capita GDP (100 million yuan) \\
\hline & & Tertiary Industry GDP ratio (\%) \\
\hline & & $\begin{array}{l}\text { Total Import And Export (ten thousand } \\
\text { US dollars) }\end{array}$ \\
\hline & & $\begin{array}{l}\text { Total Retail Sales of Social Consumer } \\
\text { Goods }(10,000 \text { yuan })\end{array}$ \\
\hline & & Average Salary of Employees (yuan) \\
\hline & & $\begin{array}{l}\text { Real Estate Development Investment } \\
\qquad(10,000 \text { yuan })\end{array}$ \\
\hline & \multirow{11}{*}{ Social justice } & $\begin{array}{c}\text { Urban Social Security Engagement Rate. } \\
(\%)\end{array}$ \\
\hline & & Number of Urban Employees $(10,000)$ \\
\hline & & Number of Public Libraries (unit) \\
\hline & & $\begin{array}{l}\text { Average Number of Secondary Schools } \\
\text { (unit) }\end{array}$ \\
\hline & & Unemployed Population $(10,000)$ \\
\hline & & Number of Health Institutions (unit) \\
\hline & & $\begin{array}{l}\text { Expenditure on Education Expenditure } \\
(10,000 \text { yuan })\end{array}$ \\
\hline & & $\begin{array}{c}\text { City Cleaning Area (10,000 square } \\
\text { meters) }\end{array}$ \\
\hline & & $\begin{array}{c}\text { Land Area of Public Facilities (square } \\
\text { kilometers) }\end{array}$ \\
\hline & & Funding Number of Participants (person) \\
\hline & & $\begin{array}{c}\text { Rural Subsistence Expenditure } \\
(10,000 \text { yuan })\end{array}$ \\
\hline & \multirow{5}{*}{$\begin{array}{l}\text { Environmentall } \\
\text { y sustainable }\end{array}$} & Urban Green Coverage (\%) \\
\hline & & Industrial Waste Water Discharge (tons) \\
\hline & & $\begin{array}{l}\text { Eco-environment Industry Social Groups } \\
\text { (unit) }\end{array}$ \\
\hline & & Garbage Disposal (\%) \\
\hline & & Per Capita Green Area (square meters) \\
\hline
\end{tabular}

\subsection{Quantitative assessment of SGL}

We apply the Minimum Relative Deviation Distance method in comprehensive evaluation model as this way does not require data pre-processing.

\subsubsection{Set up the relative deviation fuzzy matrix}

The ideal alternative is

$$
\mathrm{c}=\left(\mathrm{c}_{1}^{0}, \mathrm{c}_{2}^{0}, \mathrm{c}_{3}^{0}, \mathrm{c}_{4, \ldots \ldots,}^{0} \mathrm{c}_{m}^{0}\right)
$$

where

$$
\mathrm{c}_{\mathrm{i}}^{0}= \begin{cases}\max \left\{a_{i j}\right\} & a_{i j} \text { is an efficiency indicator } \\ \min \left\{a_{i j}\right\} & a_{i j} \text { is a costindicator }\end{cases}
$$

Set up the relative deviation fuzzy matrix with $R=\left(r_{i j}\right)_{m \times n}$, where $\mathrm{m}$ is the number of Cities, $\mathrm{n}$ is the number of indicators.

$$
r_{i j}=\frac{\left|a_{i j}-u_{i}^{0}\right|}{\max \left\{a_{i j}\right\}-\min \left\{a_{i j}\right\}} .
$$

\subsubsection{Evaluation Model Based on Variation coefficient method}

In this paper, variation coefficient method is adopted to calculate the weight vector in this section.

The coefficient of variation of each index is

$$
v_{i}=\frac{s_{i}}{\left|\begin{array}{c}
- \\
x_{i}
\end{array}\right|}
$$

Where

$$
\bar{x}_{i}=\frac{1}{n} \sum_{j=1}^{n} a_{i j}
$$

is the average of the $i_{t h}$ index,

$$
s_{i}=\sqrt{\frac{1}{n-1} \cdot \sum_{j=1}^{n}\left(a_{i j}-\overline{x_{1}}\right)^{2}} \text {. }
$$

is the variance of the $i_{t h}$ index

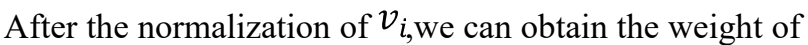
each index:

$$
w_{i}=\frac{v_{i}}{\sum_{i=1}^{m} v_{i}}
$$

After the determination of weight of the indicators by variation coefficient method, the evaluation model of SGL is established.

$$
S G L=1-\sum_{\mathrm{i}=1}^{22} w_{i} r_{i j} \quad(j=1,2,3, \cdots, 70)
$$

The result is shown in Figure.6. and Figure.7.

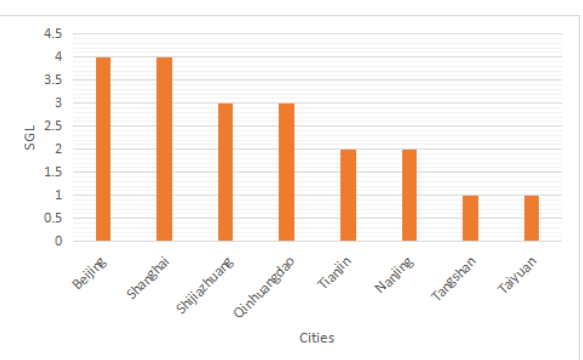

Figure.6. The SGL of some cities.

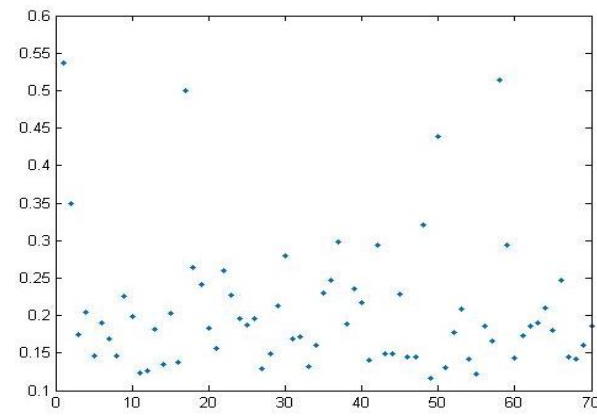

Figure. 7. The SGL of 70 mid-scale and large cities in China. 
The larger SGL is, the development model of given city meets the requirements of Smart Growth better.

\section{The Standard of Smart Growth}

According to the SGL evaluation model aforementioned, we can get the standard of smart growth using K-means clustering method. Then the mean of the indicator centres is used as the standard boundary.

In this way, 70 cities are divided into for kinds: outstanding, good, normal and terrible. Terrible means that the development model has limited and threated the further development of given city. Normal means that the city has not realized smart growth in this area. And good means that the city has some success of smart growth in this area. Outstanding is used to describe when city has great success of smart growth. The standard of SGL and the classification of 70 mid-scale and large cities in China is shown in Table.3. and Table.4.[12][13]

Table. 3. The standard of SGL

\begin{tabular}{|c|c|}
\hline Grade & SGL \\
\hline terrible & $0 \sim 0.175$ \\
\hline normal & $0.175 \sim 0.252$ \\
\hline good & $0.252 \sim 0.435$ \\
\hline outstanding & $0.435 \sim 1$ \\
\hline
\end{tabular}

Table. 4. The classification of 70 mid-scale and large cities in China

\begin{tabular}{|c|c|}
\hline Grade & City \\
\hline Outstand & $\begin{array}{l}\text { Beijing, Shanghai, Shenzhen } \\
\text { Chongqing }\end{array}$ \\
\hline Good & $\begin{array}{l}\text { Tianjin, Nanjing, Hangzhou, } \\
\text { Xiamen, Yantai, Wuhan } \\
\text { Guangzhou, Chengdu }\end{array}$ \\
\hline Normal & $\begin{array}{l}\text { Tangshan, Taiyuan, Shenyang, } \\
\text { Dalian, Changchun, Harbin, Wuxi, } \\
\text { Xuzhou, Ningbo Wenzhou, } \\
\text { Jinhua, Hefei, Fuzhou Jinan, } \\
\text { Qingdao, Jinan, Zhengzhou, } \\
\text { Luoyang, Changsha Huzhou, } \\
\text { Nanning, Haikou Guizhou, } \\
\text { Zunyi, Kunming, Dali Xian, } \\
\text { Urumchi }\end{array}$ \\
\hline Terrible & $\begin{array}{l}\text { Shijiazhuang, Hohehot, } \\
\text { Municipality, Baotou, Dandong, } \\
\text { Jinzhou, Jilin, Mudanjiang } \\
\text { Yangzhou, Bengbu, Anqing } \\
\text { Quanzhou, Nanchang, Jiuzhou } \\
\text { Ganzhou, Pingdingshan Yichang, } \\
\text { Xiangyang, Yueyang } \\
\text { Changde, Shaoguan, Zhanjiang } \\
\text { Guilin, Beihai, Sanya, Luzhou } \\
\text { Nanchong, Lanzhou, Xining } \\
\text { Yinchuan }\end{array}$ \\
\hline
\end{tabular}

\section{Conclusion}

There exits a great difference in the model and level of cities' development in China. Specifically speaking, some cities like Beijing and Shanghai have achieved great success of smart growth while some of others like Yueyang and Lanzhou are suffering from a bottleneck period in pursuing development. Positive measures and smart growth plan should be adopted to help these cities to achieve smart growth.

\section{Acknowledgements}

Jie Min acknowledges the support from Chinese Natural Science Foundation (Grant No. 71571002).

\section{References}

1. Jan B S. Interdependencia de la expansión urbana y el medio ambiente circundante. Causas de su degradación Interdependance of urban sprawl and surrounding environment. Causes for its Degradation Interdependência da expans o urbana e do meio ambiente. Causas da $\mathrm{s}[\mathrm{J}]$. Cuadernos De Vivienda Y Urbanismo, 2011, 4(8).

2. EPA,"This is Smart Growth"2016 https://www.epa.gov/smartgrowth/smart-growthpublication

3. C. Badii,P. Bellini,D. Cenni,A. Difino,P. Nesi,M. Paolucci. Analysis and assessment of a knowledge based smart city architecture providing service APIs[J]. Future Generation Computer Systems,2017,75.

4. Anna Luusua,Johanna Ylipulli,Emilia Rönkkö. Nonanthropocentric design and smart cities in the anthropocene[J]. it - Information Technology,2017,59(6).

5. Chang Saisai, Hu Guanxi, Kang Junwei, Lu Jingyi, Zhao Run. Construction of intelligent growth indicator system based on fuzzy comprehensive evaluation [J]. Computer knowledge and technology, 2013,13(13):176-178.

6. China Economic and Social Development Statistics Database

7. http://tongji.cnki.net/kns55/index.aspx

8. He Y. Study on the Solution and Precision of Model GM(1,1)[J]. Systems Engineering, 1993.

9. Talen E, Knaap G J. Legalizing Smart Growth: An Empirical Study of Land Use Regulation in Illinois[J]. Journal of Planning Education \& Research, 2003, 22(4):345-359.

10. Edwards M M, Haines A. Evaluating Smart Growth: Implications for Small Communities[J]. Journal of Planning Education \& Research, 2007, 27(1):49-64.

11. Chen D D T. The Science of Smart Growth[J]. Scientific American, 2000, 283(283):84-91.

12. Nielsen E S. Sprawl and Smart Growth[J]. 2017.

13. Kanungo T, Mount D M, Netanyahu N S, et al. An efficient k-means clustering algorithm: analysis and implementation[J]. IEEE Transactions on Pattern Analysis \& Machine Intelligence, 2002, 24(7):881892. 
14. [ Hartigan J A. A K-Means Clustering Algorithm[J]. Appl Stat, 1979, 28(1):100-108 